\title{
An imbalance in Akt/mTOR is involved in the apoptotic and acantholytic processes in a mouse model of pemphigus vulgaris
}

\author{
Maider Pretel ${ }^{1}$, Agustín España ${ }^{1}$, Miren Marquina ${ }^{1}$, Beatriz Pelacho², Jose María \\ López-Picazo ${ }^{3}$ and Maria J. López-Zabalza ${ }^{2}$ \\ ${ }^{1}$ Department of Dermatology, University Clinic of Navarra, School of Medicine, \\ University of Navarra, Navarra, Spain; \\ ${ }^{2}$ Department of Biochemistry, University Clinic of Navarra, School of Medicine, \\ University of Navarra, Navarra, Spain; \\ ${ }^{3}$ Department of Oncology, University Clinic of Navarra, School of Medicine, University \\ of Navarra, Navarra, Spain
}

Correspondence:

Agustín España, Department of Dermatology, University Clinic of Navarra, School of Medicine, University of Navarra, PO Box 4209, Pamplona 31080, Navarra, Spain, Tel.: +34 94825 5400, Fax: +34 94829 6500, e-mail: aespana@unav.es

\begin{abstract}
Pemphigus vulgaris (PV) is an autoimmune blistering disease characterized by the presence of IgG autoantibodies againstDsg3. Our aim was to investigate the molecular events implicated in the development and localization of apoptosis and acantholysis in PV. We used a passive transfer mouse model together with immunohistochemical (IHC) techniques and the TUNEL assay, with quantification analysis in the basal layer of the epidermis. The activated signalling molecules analysed and apoptotic cells detected showed an identical localization. Herein, we found for the first time in vivo an increased expression of activated HER receptor isoforms in the basal layer in PV lesions. Besides, we observed the almost total lack of activated Akt compared with a higher level of activated mTOR within the basal cells of the epidermis. Our observations strongly support that the restriction of acantholysis to the basal layer may be due, at least in part, to the selective and increased presence of activated HER receptor isoforms in these cells. After phosphorylation of HER receptor isoforms, intracellular signalling pathways are activated in the basal layer. In addition, the imbalance in AktmTOR that takes place in the basal cells may provide intracellular signals necessary for the development of apoptosis and acantholysis.
\end{abstract}

Key words: Akt, HER isoforms, mTOR, pemphigus vulgaris, Src 


\section{INTRODUCTION}

Pemphigus vulgaris (PV) is an autoimmune mucocutaneous disease characterized by intraepidermal blisters and autoantibodies against desmosomal cadherin desmoglein (Dsg) 1 andor $3(1,2)$. The mechanisms of blister formation in PV are still uncertain. It has long been known that the IgG fraction of patients' sera is necessary and sufficient to produce acantholysis in in vivo experimental models (3). Müller et al. have recently postulated that PV-IgG against extracellular domains of Dsg3 relates to type of PV (4). Acantholysis is triggered in suprabasal keratinocytes through mechanisms mediated by the PV-IgG, including: direct inhibition of the extracellular Dsg3 adhesive ability of autoantibodies binding to Dsg3 andor interference of desmosomal cadherin-bound autoantibodies with intracellular signalling pathways (5). Moreover, the multiple-hit (6) and basal cell shrinkage hypotheses (7) reconcile recent findings related to the pathogenesis of PV.

Receptor tyrosine kinases (RTK) are a subgroup of transmembrane proteins with an intrinsic tyrosine kinase activity which determines several cellular functions as diverse as growth, differentiation, cell motility, cellular adhesion or survival (8). The epidermal growth factor receptors (EGFR) family of RTKs consists of four members: EGFR (also known as ErbB1 or HER1), ErbB2 (HER2), ErbB3 (HER3) and ErbB4 (HER4). They are activated by the ligand- or non-ligand-dependent form (8). It is interesting to underline that HER receptors acquire distinct intracellular signalling properties depending on their dimerization partner (9). The three best characterized intracellular signalling pathways induced through HER receptors are mitogen activated proteinkinases, phosphatidylinositol-3-kinase/protein-kinase B and phospholipase C-protein kinase C pathways (10). Several studies using cultures of keratinocytes have provided evidence for a role of the epidermal EGFR in the assembly or disassembly of the adherens and desmosomal junctions (11-13). EGFR may be involved in the activation of intracellular pathways in the acantholytic process in PV $(14,15)$. In addition, Src kinase may also take part in PV acantholysis by phosphorylation of EGFR and also by mediating keratin aggregation of keratinocytes as well (15).

Apoptosis is a process characterized by a series of dramatic perturbations to the cellular architecture that con-tribute not only to cell death, but also prepare cells for removal by phagocytes and prevent unwanted immune responses (16). In several studies, an activation of the apoptosis mechanism in acantholytic PV cells has been observed $(14,17-20)$. Akt and mTOR kinases have been involved in the regulation of cell survival, and they are considered as mediators of survival or death of cells (21-24). In fact it is known that mTOR integrates signals mediated by growth factors, and is involved in signalling downstream of Akt in PI3K pathway. It has also been described that mTOR may take part in the apoptotic pathway activated by damaged microtubules (25). The role of mTOR may be shown as part of the mTORC1 and mTORC2 complexes (26).

Currently, in vivo experiments using the EGFR inhibitor erlotinib (27), the mTOR inhibitor rapamycin (28), the Src inhibitor PP1 (29) and pan-caspase inhibitors (30) have been successfully employed to explore the involvement of these signalling molecules in several inflammatory diseases. 
Based on the above findings, our aim in this study was to explore if the increased level of activated HER receptor isoforms, PI3K/Akt pathway and mTOR kinase activity may take part in both apoptotic and acantholytic processes in PV lesions in a mouse model. Herein, we observed for the first time in vivo an increase of activated HER isoforms other than EGFR in the basal cells of the epidermis after injection of PV-IgG in mice. Furthermore, our findings revealed that the imbalance in AktmTOR activities caused by PV-IgG within the basal cells may provide the intracellular signals necessary for the development of apoptosis and acantholysis in PV. This AktmTOR imbalance may depend on the activation of HER receptor isoforms and the downstream intracellular signalling pathways subsequently triggered in basal cells. Moreover, the activation of HER receptors in basal cells together with the absence of Akt in these cells may explain the restriction of acantholysis to the basal layer of epidermis in PV.

\section{MATERIAL AND METHODS}

\section{Human sera}

Our study was based on experiments utilizing IgG fractions isolated from sera of three PV patients with active lesions on oral mucosa and skin, and serum of a healthy donor [normal human serum (NHS)]. The Ethics Committee of the University Clinic of Navarra approved this study. All of the three patients gave their signed consent to use their sera for experimental studies. The three sera contain IgG against the epidermal intracellular substance, showing the indirect IF titre of 1.320 for PV1, 1:640 for PV2 and 1:320 for PV3. All PV sera contained IgG autoantibodies to Dsg1 and Dsg3 as determined by ELISA (MBL Naka-Ku, Nagoya 460-002, Japan) and immunoprecipitation (31). Normal donor serum showed negative anti-epidermal autoantibody titre and anti-Dsg1 and anti-Dsg3 antibodies were not found.

IgG fractions from the PV patients and the normal human donor were prepared as previously described elsewhere (31). Briefly, IgG fractions were precipitated with 50\% ammonium sulphate, followed by affinity chromatography on Staphylococcus protein A conjugated to agarose beads. Bounded IgG was eluted with $0.2 \mathrm{M}$ glycine/HCl, pH 3, dialysed extensively against phosphate-buffered saline (PBS), $\mathrm{pH} 7.4$, concentrated by ultrafiltration (Amicon, Beverly, MA, USA), filter-sterilized and stored at $-40^{\circ} \mathrm{C}$ until use. Protein concentration was determined by the Bradford assay (32). The IgG concentration in each fraction was estimated by nephelometry using goat anti-human IgG (Beckman Array 360 System, Holliston, MA, USA).

\section{Testing IgG pathogenicity using the passive transfer animal model}

C57BL6J mice were obtained from The Jackson Lab (Bar Harbor, ME, USA). The study was performed in 24- to 48-h-old neonatal mice (weighing 1.5-2.0 g) from a colony maintained at the Centre of Animal Control at the University of Navarra. Each IgG fraction was tested for pathogenicity by passive transfer experiments as previously described elsewhere. (31) IgG from all of the three PV and NHS sera was injected intradermally into the neonatal mice ( $2 \mathrm{mg} / \mathrm{g})(\mathrm{n}=3$ for each IgG) and evaluated $12 \mathrm{~h}$ later for evidence of skin blisters. This time interval for the evaluation of mice was based on a time course study, which demonstrated that suprabasal acantholytic process was evident $11 \mathrm{~h}$ after the injection of PV-IgG fractions. Following examination of the 
skin for blisters, animals were killed. Clinical activity in mice was evaluated [Nikolsky's sign (Ns)] according to the following scale: no spontaneous disease and negative Ns (0), no spontaneous disease and slight Ns (1+), slight spontaneous disease and slight Ns (2+) and important spontaneous disease and positive Ns (3+). Skin biopsies from each animal included lesional skin samples for routine histological examination by haematoxylin/eosin (H\&E) and immunohistochemical (IHC) staining, and immunofluorescence (IF) techniques. Histological examination was evaluated following this scale: no acantholysis (0), acantholysis in less than one-third of the skin biopsy (1+), acantholysis between one- and two-thirds of the biopsy (2+) and acantholysis in more than two-thirds of then biopsy (3+). Direct IF was considered as either positive or negative.

\section{Inhibitor treatment schedule}

All inhibitors were administered by a single intradermal injection into the back of mice 2 h before PV-IgG administration, as described elsewhere (31). Inhibitors were diluted in DMSO and injected into mice ( $\mathrm{n}=3$ for each inhibitor) at the following doses based on in vivo studies reported elsewhere: erlotinib, $100 \mu / \mathrm{g}$ body weight (EGFR, HER2 and HER3 inhibitors, kindly provided by OSI Pharmaceuticals, and the purity was $>95 \%$ ) (27); mTOR activity inhibitor rapamycin, $5 \mu / \mathrm{g}$ body weight (Calbiochem, Darmstadt, Germany) (28); Src activity inhibitor PP1, $1 \mu / \mathrm{g}$ body weight (Calbiochem) (29) and pan-caspase inhibitor (cpmVAD-CHO), $1.6 \mu / \mathrm{g}$ body weight (Calbiochem) (30). Mice were killed $12 \mathrm{~h}$ after administration of PV-IgG fractions.

\section{Immunohistochemical staining procedure}

Tissue samples for IHC staining were fixed in zinc solution $(0.1 \mathrm{~m}$ Tris buffer $\mathrm{pH} 7.4$, $0.5 \mathrm{~g}$ calcium acetate, $5.0 \mathrm{~g}$ zinc acetate, $5.0 \mathrm{~g}$ zinc chloride, $\mathrm{pH}$ 6.7-7.0). A tissue microarray was constructed from each specimen in the cohort. Tissue cores $2 \mathrm{~mm}$ in size were obtained from paraffin-embedded tissue blocks. The original H\&E stained slides from all blocks were first reviewed under microscope to select representative areas of the skin. The cores were placed on the recipient microarray block using a Tissue Microarrayer (Beecher Instrument, Silver Spring, MD, USA). All specimens were represented with fourfold redundancy. The tissue microarray was then routinely sectioned at $4 \mathrm{~lm}$ thickness. These sections were dewaxed with xylene and rehydrated with graded ethanol. Endogenous peroxidase activity was blocked with 3\% hydrogen peroxidase for $10 \mathrm{~min}$. Before the IHC procedure, all antibodies were required for antigen retrieval. All sections were placed either in a citrate buffer $10 \mathrm{~mm}(\mathrm{pH} \mathrm{6.0)}$ and heated in a microwave oven (Balay W-2112, 1150-700W; Madrid, Spain) for 15 min at maximum power and for 15 min at medium power, or in an EDTA buffer $1 \mathrm{~mm}(\mathrm{pH}$ 8.0) and heated in a microwave oven for $5 \mathrm{~min}$ at maximum power and for $15 \mathrm{~min}$ at medium power. Background blocking was performed with 1:20 normal goat serum (DAKO, Glostrup, Denmark) prior to incubation with specific antiserum. Tissue sections were incubated with different polyclonal antibodies purchased from Cell Signaling, Barcelona, Spain, and specific for: P-EGFR (Tyr992), dilution 1:100, EDTA; P-HER2 (Tyr877), dilution 1:50, EDTA; P-HER3 (Tyr1289), dilution 1:100, EDTA; PmTOR (Ser2448), dilution 1:50, citrate; P-Src (Tyr416), dilution 1:100, EDTA and PAkt (Ser473), dilution 1:50, citrate. In addition, the following polyclonal antibodies were purchased from R\&D Systems, Inc, Abingdon, UK: betacellulin (AF989), dilution 1:50, citrate; EGF (AF2028), dilution 1:20, EDTA; amphiregulin (AF1025), dilution 
1:20, EDTA; neuroregulin 3 (AF753), dilution 1:100, EDTA. Finally, mouse anti-TGFa polyclonal antibody was purchased from Gene Tex, Inc, TX, USA (GTX16768), dilution 1:200, EDTA. Sections were incubated overnight at $4^{\circ} \mathrm{C}$ with the primary antisera. The detection system used was the Envision method (K4011; Dako, CA, USA) consisting of a goat anti-rabbit or antimouse IgG secondary antibody coupled to a peroxidase labelled dextran polymer. Sections were incubated with this reagent for 30 min at room temperature and successively washed in PBS for 5 min. Peroxidase activity was revealed using Vector VIP detection kit (SK4600; Vector, Orton Southgate, Peterborough, UK). The reaction was stopped by washing the sections in PBS. The sections were lightly counterstained with haematoxylin, dehydrated and mounted with DPX (Sigma- Aldrich, St. Louis, MO, USA). The ratio of stained cells on the basal layer (area of stained basal keratinocytes/area of total basal keratinocytes) was calculated using image analysis software on images acquired with a motorized Axioplan 2ie microscope (Zeiss, Oberkochen, Germany), operated through Meta-Morph imaging software (Molecular Devices, Downing-town, PA, USA) and fitted with a Zeiss Axio Cam ICc3 camera connected to a PC equipped with image-capturing software. Image analysis was performed with Matlab Software (The MathWorks Inc, Natick, MA, USA). The segmentation algorithm was custom-designed by Dr Ortiz-de-Solorzano's Morphology and Imaging Laboratory (CIMA, University of Navarra) (33).

\section{TUNEL assay}

To evaluate apoptosis, after injection of PV and NHS-IgG fractions, and each inhibitor plus PV-IgG fractions, samples of mice tissues were fixed in zinc solution as explained earlier. The TUNEL assay was carried out following the instructions of the manufacturer for ApogTag ${ }^{\circledR}$ Plus peroxidase in situ apoptosis detection kit (S7101; Chemicon International Inc., Temecula, CA, USA), and using Vector Vip as peroxidase substrate (SK4600; Vector). In addition, a time course study of apoptotic process was performed in mice after injection of PV-IgG fractions. Quantitation of numbers of TUNEL-positive cells in the basal layer of the epidermis was carried out using MetaMorph imaging software, as described earlier.

\section{Statistical analysis}

Data were analysed using the spss software for Windows (SPSS Inc, Chicago, IL, USA). Data showing a normal distribution after assessment by the Shapiro-Wilks test were analysed using a Student's t-test and if data did not show normal distribution, a non-parametric Mann-Whitney U-test was performed. Data are expressed as mean \pm SD. Significance was assumed when $\mathrm{P}<0.05$.

\section{RESULTS}

Testing IgG pathogenicity using the passive transfer animal model

The administration of purified NHS-IgG to mice showed neither clinical (Fig. 1a) nor histological detachment (Fig. 1b), and no staining for IgG by direct IF assay was detected. As was described in the section Materials and methods, the time for evaluation of mice in this study was based on our previous analyses of time course for clinical and histological findings after PV-IgG administration. Suprabasal acantholysis became 
evident $11 \mathrm{~h}$ after PV-IgG injection. Therefore, all studies in our experiments in mice were carried out $12 \mathrm{~h}$ after PV-IgG injection. All mice studied presented important Ns sign after $12 \mathrm{~h}$ of PV-IgG injection $(+++/+++)$ (Fig. 1c). All samples of skin from PVIgG injected studied mice revealed suprabasal acantholysis in the epidermis $(+++/+++)$ (Fig. 1d). All samples of perilesional skin obtained for direct IF assays demonstrated pericellular staining for IgG in basal and suprabasal cells.

Increased levels of activated HER receptor isoforms in basal cell layer of epidermis after PV-IgG administration of mice

Although some authors have described an increase of P-EGFR (P-HER1) in keratinocytes after PV-IgG administration, no study has analysed both the localization and level of activated HER isoforms in the basal cells of the epidermis in a PV mouse model. Therefore, firstly we studied how and where the P-HER isoforms are expressed in epidermis after NHS-IgG and PV-IgG administration to mice. After NHS-IgG injections, a scattered and very slight staining for P-HER1, P-HER2 and P-HER3 was observed in the basal layer of the epidermis (Fig. 2a). However, this staining was particularly strong in detached and non-detached basal layer of epidermis when mice were injected with PVIgG (Fig. 2a). A most interesting finding in our study was the significant elevation $(\mathrm{P}<0.05)$ of the levels of all PHER isoforms after PV-IgG administration to mice, when compared with that in mice injected with NHS-IgG (Fig. 2b).

To establish a possible correlation between the P-HER isoforms activity and activation of downstream intracellular signalling pathways in basal keratinocytes in PV, we studied the effect of P-HER inhibitor erlotinib (inhibitor of P-HER1, P-HER2 and PHER3) in both clinical manifestations and the acantholytic process in mice. We could find no evidence of detachment of epidermis (Ns) (Fig. 1e) or suprabasal acantholysis (Fig. 1f). In addition, an important and significant decrease in the levels of all P-HER isoforms $(\mathrm{P}<0.05)$ in basal cells of epidermis was observed when mice pretreated with erlotinib plus PV-IgG were compared with mice treated with only PV-IgG (Fig. 2a,b).

\section{Betacellulin, TGF-a and EGF are increased in basal layer of epidermis in PV lesions}

After observing that activated HER1, HER2 and HER3 receptors exhibit an important and relevant expression in basal cells of epidermis in PV lesions, we decided to explore if some of the potential ligands of HER isoforms may switch on intracellular network signalling in basal keratinocytes in PV lesions. Most of the ligands studied showed a slight pericellular expression on the membrane of the basal cells of the epidermis after NHS-IgG administration to mice (Fig. 3a). After PV-IgG administration, only betacellulin, EGF and TGF-a showed an enhanced and significant $(\mathrm{P}<0.05)$ expression in basal layer of epidermis when compared with mice treated with NHS-IgG (Fig. 3b).

Activated Src kinase is increased in acantholytic and non-acantholytic basal cells of the epidermis in PV lesions

In addition, we investigated the relationship between the presence of P-Src and HER isoforms activity. Firstly, we found that P-Src was expressed in the basal cells of the 
epidermis both after PV-IgG and NHS-IgG administration to mice (Fig. 4a). However, a significant increased staining for P-Src was observed in the former $(\mathrm{P}<0.05)$ (Fig. 4b). To determine if the activity of HER may affect Src activation, we pretreated mice with erlotinib (P-HER1, P-HER2 and P-HER3 inhibitor) before PV-IgG injection. We observed that P-Src levels in epidermis of these mice were significantly lower than that found when only PV-IgG was administered $(\mathrm{P}<0.05)$ (Fig. 4a,b). These results indicated that Src kinase may be activated in the basal cells of the epidermis in PV lesions in a mouse model, at least in part, directly through P-HER receptors. In addition, we found that mice pretreated with Src inhibitor PP1 showed neither clinical lesions (positive Ns) (Fig. 1g) nor histological acantholysis (Fig. 1h).

\section{An imbalance in Akt/mTOR activities is present in the basal cells of the epidermis in PV lesions}

The next step was to elucidate if the PI3K/Akt signalling pathway is activated in the basal layer of epidermis after HER receptor activation in PV lesions. We determined the levels of P-Akt and P-mTOR in the basal cells of the epidermis after PV-IgG injection in mice, and how these signalling molecules are affected by pretreatment with several inhibitors. Firstly, we detected that there was hardly any P-Akt staining in the basal cells of the epidermis after NHS-IgG or PV-IgG administration (Fig. 5a). Expression of P-Akt was found only in the granular layer of the epidermis. The staining for P-mTOR was scattered across the basal layer of the epidermis after administration of NHSIgG, whereas it was strong in the same localization after PV-IgG injection (Fig. 5a). Using quantification analysis, we observed that the level of P-Akt was similar and very low in the basal layer of the epidermis after both NHS-IgG and PV-IgG administration and also after PV-IgG plus erlotinib or PP1 injection (Fig. 5b). However, after PV-IgG injection, the level of P-mTOR was significantly higher in the same localization $(\mathrm{P}<$ 0.05) than that detected after NHS-IgG injection (Fig. 5b).

In addition, we wondered whether mTOR is activated through the HER receptor isoforms downstream pathways or whether other signalling molecules such as Src may take part in mTOR activation, as has been described elsewhere (34). Firstly, mice were pretreated with the HER inhibitor erlotinib, and a significant decrease in the P-mTOR levels $(\mathrm{P}<0.05)$, in comparison with that of mice treated only with PV-IgG, was observed (Fig. 5a,b). Secondly, mice were pretreated with the Src inhibitor PP1. In these mice we found significant decreased levels of P-mTOR $(\mathrm{P}<0.05)$ as compared with that in mice injected only with PV-IgG (Fig. 5a,b).

To determine how P-mTOR contributes to PV lesions in basal acantholytic cells of the epidermis, we pretreated the mice with the mTOR inhibitor rapamycin and then injected them with PV-IgG. None of these mice showed Ns (Fig. 1i) and suprabasal acantholysis (Fig. 1j).

\section{Apoptosis appears before acantholysis in PV lesions, and may be abolished by erlotinib, rapamycin, PP1 and pan-caspase inhibitor}

Apoptotic cells in the basal layer of the epidermis were detected $8 \mathrm{~h}$ after PV-IgG administration to mice, and $3 \mathrm{~h}$ before the acantholytic process began (Fig. 6a). The increased levels of apoptotic cells in the basal layer of the epidermis after PV-IgG 
administration were statistically significant compared with the levels obtained after administration of NHS-IgG $(\mathrm{P}<0.05)$ (Fig. 6c). Although several studies have described the inhibition of the acantholytic process induced by PV-IgG by pretreatment with caspase inhibitor, these findings have been observed only in vitro models. Therefore, our next step was to determine whether the same findings were applicable in an in vivo model. Furthermore, we wanted to clarify the relationship between apoptosis/acantholysis in our model by means of the administration of a pan-caspase inhibitor to mice. We found that pretreatment of mice with this inhibitor led to a complete absence of PV lesions as determined by clinical (Fig. 1k) and histological examination (Fig. 11).

In addition, when mice were pretreated with erlotinib, rapamycin, PP1 or pan-caspase inhibitor, a significant $(\mathrm{P}<0.05)$ decreased expression of apoptotic cells in the basal cells of the epidermis was observed by quantification analysis of TUNEL assays, when these mice were compared with those treated only with PV-IgG (Fig. 6b,c).

\section{DISCUSSION}

The molecular mechanism of the blistering process in PV is not fully understood. Several studies have demonstrated that acantholysis is associated with the presence of apoptotic cells $(14,17-20)$. Nevertheless, it is not fully clear how these two processes are related to each other in PV lesions.

Recently, it has been suggested that different characteristics of basal and suprabasal keratinocytes, with the expression of surface receptors on the basal cell layer (7), and the activation of intracellular signalling pathways, may explain the selective suprabasal acantholysis in PV (6). Our findings show that the restriction of acantholysis to the basal layer is not only due to a sharp morphological difference between basal and suprabasal cells. We provide evidence that apoptotic and acantholytic processes are a consequence of both molecular differences between basal and suprabasal cells and molecular changes created in the basal layer of the epidermis after PV-IgG binding to cells.

Under normal physiological conditions, HER1 expression is found mainly in the cells of the basal layer of the epidermis $(35,36)$. HER2 is normally expressed in basal cells of the epidermis and the outer root sheath of hair follicles (37). In addition, HER3 appears to be expressed in all layers of the human and mouse epidermis, although expression is predominantly limited to the suprabasal layer (38). HER4 is not usually expressed in the epidermis. In our study, after PV-IgG injection to mice, P-HER1, P-HER2 and P-HER3 showed a significant and stronger staining in the basal layer of the epidermis than that observed after NHS-IgG administration. Previously, it has also been described in vitro that EGFR (HER1) is activated after PVIgG binding to basal cell antigens $(14,15)$. Moreover, the inhibition of both apoptotic and acantholytic processes observed by erlotinib pretreatment of mice (inhibitor of HER1, HER2 and HER3) $(39,40)$ underlines the important role of P-HER isoforms activity in PV lesions in our model. Based on these and our findings, we may speculate that P-HER receptors in the basal layer of the epidermis may trigger distinct intracellular signalling pathways leading to apoptosis and acantholysis. 
HER receptors may switch on intracellular network signalling through two different mechanisms. Growth factors may stimulate HER-expressing cells through either paracrine or autocrine mechanisms. Besides, HER activation may be independent of ligands binding to the receptor. This mechanism of HER activation entails stimulation of cytoplasmic tyrosine kinases, such as the Jak and Src family kinases (41). Our study shows that HER receptors in PV lesions may be activated through a ligand-dependent form. In mammals, each HER ligand contains an EGF-like domain that confers binding specificity $(36,42)$. Of all the ligands tested in our study of PV in vivo, we could observe an important and significant enhancing only for betacellulin, while TGF-a and EGF did not previously describe in PV. The precise role of these three ligands in epidermis is still unknown in PV lesions. Recently, betacellulin has been implicated in the regulation of hair follicle development and hair cycle induction and enhances angiogenesis in wounded skin (43); TGF-a and EFG may take part in proliferating and regulating epidermal tissue regeneration $(44,45)$. Usually, these three ligands show a higher affinity for HER1/2 than other HER isoforms, and probably biregulin and heregulin present more affinity for HER3 (42).

After the binding of these ligands to their receptors, selective activation of intracellular signalling pathways in the basal cells of the epidermis has been observed (46). We do not know nevertheless if up-regulation of these ligands was caused by PV-IgG binding to keratinocytes before acantholysis or if it was induced by cell dissociation. And the origin of these ligands is not yet clear, keratinocytes or some other cells. This point indeed is an exciting objective for future research projects on PV.

Recently, a study has established that early events in acantholysis in PV are mediated by Src activation through phosphorylation of EGFR, and are associated with collapse of the cytoskeleton (15). On the contrary, other study (47) has suggested that the loss of Dsgmediated adhesion and keratinocyte dissociation in PV is independent of EGFR and SrC activities. Our study demonstrated an increased and significant presence of P-Src in cells of the basal layer of the epidermis after PV-IgG administration. As this increase of P-Src was abolished by erlotinib pretreatment (inhibitor of HER isoforms activity), Src activation seems to be HER-dependent. Furthermore, we were able to abolish the PVIgG-induced apoptotic and acantholytic processes by PP1 pretreatment to mice (inhibitor of Src activity). Thus, these results are in agreement with previous observations and show a relevant molecular role of P-Src in the activation of intracellular signalling cascades in PV lesions in a mouse model $(15,48)$.

A large body of evidence supporting the role of EGFR and activation of mTOR in cell growth and proliferation in keratinocytes has been reported $(49,50)$. However, some studies have demonstrated that mTOR could also mediate the apoptotic process (25). On the other hand, up-regulation of P-Akt promotes survival of cells types, among them keratinocytes (51), by regulation of some pro-apoptotic proteins such as Bad and the transcription factor FKHRL-1 (21,52). Although PI3K/Akt pathway is considered to be a key activator of mTOR (10), the data presented in the current study suggest that mTOR kinase phoshorylation could have been produced by a mechanism independent of this pathway in basal cells of PV lesions. Firstly, a most interesting finding in our study was the observation of an almost total lack of P-Akt presence in basal cells of PV lesions, similar to that observed after NHS-IgG injection, or erlotinib, rapamycin and PP1 plus PV-IgG administration. This could be explained by the fact that usually Akt is expressed in suprabasal and parabasal cells (postmitotic cells) in neo-natal mice 
epidermis, but not in epidermal basal cells as has been previously reported (24). In this sense, activation of PI3K/Akt pathway has been found to be a key determinant of keratinocyte differentiation only in suprabasal cells of the epidermis, when postmitotic basal cells have initiated movement towards the spinous epidermal layer (24). All of these data support that the very low activity of Akt may play a role in PV lesions in the basal acantholytic cells of the epidermis. Therefore, after HER activation by PV-IgG binding to basal cells, an imbalance in Akt/mTOR may be generated as a consequence of the up-regulation of mTOR in cells with a very low activity of Akt, driving the cells to apoptosis. Our observation of a significant decrease in P-mTOR with no change in PAkt, associated with an important reduction of apoptosis and inhibition of acantholysis in the basal layer of the epidermis after erlotinib pretreatment, corroborates this suggestion. In addition, the importance of the imbalance in AktmTOR activities in PV lesions is highlighted with our observation of inhibition of acantholytic and apoptotic processes, with no change of P-Akt, in the basal layer by rapamycin pretreatment (an inhibitor of P-mTOR activity). Finally, another interesting finding in our study was the inhibition of apoptotic and acantholytic processes in the basal cells layer of the epidermis by pretreatment with PP1, associated with down-regulation of P-mTOR and with no change in P-Akt. These results suggest that in our model mTOR may be regulated by Src kinase, as has been described by others (34). Thus, it is tempting to speculate that PV-IgG causes an imbalance in Akt/mTOR activities within the basal cells of the epidermis, at least in part, as a consequence of HER receptor downstream signalling with activation of mTOR mediated by P-Src, without up-regulation of Akt in these cells. The precise roles of mTOR, as part of the mTORC1 and mTORC2 complexes, are not yet completely understood. Taking into account that both mTORC1 and mTORC2 may be stimulated by growth factors and that the mechanism of action of mTOR inhibitor rapamycin depends on the type of mTOR complex $(53,54)$, further studies would be necessary to know how this kinase participates in the development of apoptosis and acantholysis processes in PV.

Some studies suggest that Fas-L and PV-IgG induce apoptosis in PV lesions through the activation of caspases $(17,18)$. Caspases may directly cleave Dsg3 and other desmosomal proteins, causing desmosome disruptions (55). In our study, we demonstrated that apoptosis may be induced by the up-regulation of P-mTOR in the basal cells of the epidermis, which has been shown to induce downstream phosphorylation of Bcl-2 (25). Our findings indicate that mTOR activation induced by PV-IgG may firstly precede and later induce activation of apoptosis, as rapamycin administration abolished apoptosis. Desmosome disruptions may appear after apoptosis (20), such as was also observed in our experiments in vivo, with apoptotic cells in the basal layer $3 \mathrm{~h}$ before suprabasal acantholysis began. This may mean that the induction of apoptosis leads to acantholysis rather than the reverse, as some authors have suggested $(20,56)$. Our observation and those from other studies $(19,52)$ of inhibition of both apoptotic and acantholytic processes after pretreatment with pan-caspase inhibitor underline the relationship between apoptosis/acantholysis in PV lesions. A recent study (57) has established that acantholysis was observed in the absence of apoptosis in skin lesions from PV patients, and hence apoptosis is not required for acantholysis in PV. The same group affirms also that PV-IgG caused dissociation of cultured human keratinocytes without evidence of altered nuclear morphology and DNA fragmentation. These findings do not coincide with those of other groups (14,17-20), including our present results. We do not know how this might be explained. Perhaps, an analysis of all these studies might lead us to explore the apoptosis mechanism in PV when we use an 
in vivo system. Only when we employ an in vivo model all potential mechanisms and signalling pathways are taking part in PV lesions. Nevertheless, further studies are necessary to clarify this issue.

In summary, although all PV patients present IgG autoantibodies against Dsg3, showing staining around keratinocytes in the lower two-thirds of the epidermis by direct IF, the restriction of apoptosis and acantholysis to the basal layer is due, at least in part, to the selective and increased activation of HER receptors in these cells. After phosphorylation of HER receptors, intracellular signalling pathways are activated in the basal layer, thereby amplifying several fold their ability to cause apoptosis and detachment of cells (58). This process is mediated, at least in part, by up-regulation of P-mTOR, without any changes of P-Akt, through a Src-dependent mechanism (Fig. 7). The inhibition of apoptosis and acantholysis observed in the basal layer of the epidermis by administration of inhibitors of HER isoforms, Src, mTOR and caspases in our model, provides compelling molecular evidence that these signalling molecules should be considered as potential therapeutic targets in PV therapy, as has recently been described (59).

\section{ACKNOWLEDGEMENTS}

We thank Professor Esteban Santiago for his contribution to the final version of this manuscript. This work was supported by a FIS grant from the Ministry of Health of Spain (PI050074).

\section{REFERENCES}

1. Stanley J R. Pemphigus and pemphigoid as paradigms of organ-specific, autoantibody-mediated diseases. J Clin Invest 1989: 83: 1443-1448.

2. Ding X, Aoki V, Mascaro J M Jr et al. Mucosal and mucocutaneous (generalized) pemphigus vulgaris show distinct autoantibody profiles. J Invest Dermatol 1997: 109: 592-596.

3. Anhalt G J, Labib R S, Voorhees J J, Beals T F, Diaz L A. Induction of pemphigus in neonatal mice by passive transfer of IgG from patients with the disease. N Engl J Med 1982: 306: 1189-1196.

4. Müller R, Svoboda V, Wenzel E, Müller H H, Hertl M. IgG against extracellular subdomains of desmoglein 3 relates to clinical phenotype of pemphigus vulgaris. Exp Dermatol 2008: 17: 35-43.

5. Sitaru C, Zillikens D. Mechanisms of blister induction by autoantibodies. Exp Dermatol 2005: 14: 861-875.

6. Grando S A. Autoimmunity to keratinocytes acathylcholine receptors in pemphigus. Dermatology 2000: 201: 290-295.

7. Bystryn J C, Grando S A. A novel explanation for acantholysis in pemphigus vulgaris: the basal cell shrinkage hypothesis. J Am Acad Dermatol 2006: 54: 513516. 
8. Prenzel N, Fischer O M, Streit S, Hart S, Ullrich A. The epidermal growth factor receptor family as a central element for cellular signal transduction and diversification. Endocr Relat Cancer 2001: 8: 11-31.

9. Hynes N E, Horsch K, Olayioye M A, Badache A. The ErbB receptor tyrosine family as signal integrators. Endocr Relat Cancer 2001: 8: 151-159.

10. Marmor M D, Skaria K B, Yarden Y. Signal transduction and oncogenesis by ErbB/HER receptors. Int J Radiat Oncol Biol Phys 2004: 58: 903-913.

11. Gaudry C A, Palka H L, Dusek R L et al. Tyrosine-phosphorylated plakoglobin is associated with desmogleins but not desmoplakin alter epidermal growth factor receptor activation. J Biol Chem 2001: 276: 24871-24880.

12. Lorch J H, Klessner J, Park J K et al. Epidermal growth factor receptor inhibition promotes desmosome assembly and strengthens intercellular adhesion in squamous cell carcinoma cells. J Biol Chem 2004: 279: 37191-37200.

13. Yin $\mathrm{T}$, Getsios S, Caldelari R et al. Mechanisms of plakoglobin-dependent adhesion: Desmosome-specific functions in assembly and regulation by EGFR. J Biol Chem 2005: 280: 40355-40363.

14. Frusic-Zlotkin $M$, Raichenberg $D$, Wang $X$ et al. Apoptotic mechanism in pemphigus autoimmunoglobulins-induced acantholysis: possible involvement of the EGF receptor. Autoimmunity 2006: 39: 563-575.

15. Chernyavsky A I, Arredondo J, Kitajima Y, Sato-Nagai M, Grando S A. Desmoglein versus non-desmoglein signaling in pemphigus vulgaris. J Biol Chem 2007: 282: 13804-13812.

16. Taylor R C, Cullen S P, Martin S J. Apoptosis: controlled demolition at the cellular level. Nature Rev 2008: 9: 231-241.

17. Puviani M, Marconi A, Cozzani E, Pincelli C. Fas ligand in pemphigus sera induces keratinocytes apoptosis through the activation of caspase-8. J Invest Dermatol 2003: 120: 164-167.

18. Pelacho B, Natal C, España A et al. Pemphigus vulgaris autoantibodies induce apoptosis in HaCaT keratinocytes. FEBS Lett 2004: 566: 6-10.

19. Wang X, Bregegere F, Frusic-Zlotkin $M$ et al. Possible apoptotic mechanism in epidermal cell acantholysis induced by pemphigus vulgaris autoimmunoglobulin. Apoptosis 2004: 9: 131-143.

20. Frusic-Zlotkin M, Pergamentz R, Michel B et al. The interaction pemphigus autoimmunoglobulins with epidermal cells. Activation of the Fas apoptotic pathway and the use of caspase activity for pathogenicity test of pemphigus patients. Ann N Y Acad Sci 2005: 1050: 371-379.

21. Franke T F, Kaplan D R, Cantley L C. PI3K. Downstream AKTion blocks apoptosis. Cell 1997: 88: 435-437.

22. Datta S R, Brunet A, Greenberg M E. Cellular survival: a play in three Akts. Genes Dev 1999: 13: 2905-2927.

23. Kim D, Chung J. Akt: versatile mediator of cell survival and beyond. J Biochem Mol Biol 2002: 35: 106-115.

24. Calautti E, Li J, Saoncella S, Brissette J L, Goetinck P F. Phosphoinositide 3kinase signaling to Akt promotes keratinocyte differentiation versus death. J Biol Chem 2005: 280: 32856-32865.

25. Asnaghi L, Bruno P, Priulla M, Nicolin A. mTOR: a protein kinase switching between life and death. Pharmacol Res 2004: 50: 545-549.

26. Huang J, Manning B D. A complex interplay between Akt, TSC2 and the two mTOR complex. Biochem Soc Trans 2009: 37: 217-222. 
27. Pollack V A, Savage D M, Baker D A et al. Inhibition of epidermal growth factor receptor-associated tyrosine phosphorylation in human carcinomas with CP358,774: Dynamics of receptor inhibition in situ and antitumor effect in athymic mice. J Pharmacol Exp Ther 1999: 291: 739-748.

28. Teachey D T, Obzut D A, Axsom K et al. Rapamycin improves lymphoproliferative disease in murine autoimmune lymphoproliferative syndrome (ALPS). Blood 2006: 108: 1965-1971.

29. Jadhav V, Matchett G, Hsu F P K, Zhang J H. Inhibition of tyrosine kinase and effect on outcomes in a new in vivo model of surgically induced brain injury. $J$ Neurosurg 2007: 106: 680-686.

30. Imao M, Nagaki M, Imose M, Moriwaki H. Differential caspase-9-dependent signaling pathway between tumor necrosis factor receptor- and Fas-mediated hepatocyte apoptosis in mice. Liver Int 2006: 26: 137-146.

31. Marquina M, España A, Fernández-Galar M, López-Zabalza M J. The role of nitric oxide synthases in pemphigus vulgaris in a mouse model. $\mathrm{Br} \mathrm{J}$ Dermatol 2008: 159: 68-76.

32. Bradford M M. A rapid and sensitive method for quantization of microgram quantities of protein utilizing the principle of protein-dye binding. Anal Biochem 1976: 72: 248-254.

33. Salas J T, Banales J M, Sarvide S et al. Ae2a,b-deficient mice development antimitochondrial antibodies and other features resembling primary biliary cirrosis. Gatroenterology 2008: 134: 1482-1493.

34. Vojtechova M, Tureckova J, Kucerova D et al. Regulation of mTORC1 signaling by Src kinase activity is Akt1-independent in RSV-transformed cells. Neoplasia 2008: 10: 99-107.

35. Green R M, Basketter D A, Couchman J R, Rees D S. Distribution and number of epidermal growth factor receptors in skin is related to epithelial cell growth. Dev Biol 1983: 100: 506-512.

36. Holbro $\mathrm{T}$, Hynes $\mathrm{N}$ E. ErbB receptors: directing key signaling networks throughout life. Annu Rec Pharmacol Toxicol 2004: 44: 195-217.

37. Kiguchi K, Bol D, Carbajal S et al. Constitutive expression of erbB2 in epidermis of transgenic mice results in epidermal hyperproliferation and spontaneous skin tumour development. Oncogene 2000: 19: 4243-4254.

38. De Potter I Y, Poumay Y, Squillace K A, Pittelkow M R. Human EGF receptor (HER) family and heregulin members are differentially expressed in epidermal keratinocytes and modulate differentiation. Exp Cell Res 2001: 271: 315- 328.

39. Kim T E, Murren J R. Erlotinib. Curr Opin Investig Drugs 2002: 3: 1385-1395.

40. Schaefer G, Shao L, Totpal K, Akita R W. Erlotinib directly inhibits HER2 kinase activation and downstream signaling events in intact cells lacking epidermal growth factor receptor expression. Cancer Res 2007: 67: 1228- 1238.

41. Mosesson Y, Yarden Y. Oncogenic growth factor receptors: implications for signal transduction therapy. Semin Cancer Biol 2004: 14: 262-270.

42. Jones J T, Akita R W, Sliwkowski M X. Binding specificities and affinities of EGFR domains for ErbB receptors. FEBS Lett 1999: 447: 227-231.

43. Schneider M R, Antsiferova M, Feldmeyer L et al. Betacellulin regulates hair follicle development and hair cycle induction and enhances angiogenesis in wounded skin. J Invest Dermatol 2008: 128: 1256-1265.

44. Maas-Szabowski N, Stárker A, Fusenig N E. Epidermal tissue regeneration and stromal interaction in HaCaT cells is initiated by TGF-alpha. J Cell Sci 2003: 116: 2937-2948. 
45. Faurschou A, Gniadecki R. TNF-alpha stimulates Akt by a distinct aPKCdependent pathway in premalignant keratinocytes. Exp Dermatol 2008: 17: 992997.

46. Yarden Y, Sliwkoski M X. Untangling the ErbB signaling network. Mol Cell Biol 2001: 2: 127-137.

47. Heupel W M, Engerer P, Schmidt E, Waschke J. Pemphigus vulgaris IgG cause loss of desmoglein-mediated adhesion and keratinocyte dissociation independent of epidermal growth factor receptor. Am J Pathol 2009: 174: 475-485.

48. Sánchez-Carpintero I, España A, Pelacho B et al. In vivo blockade of pemphigus vulgaris acantholysis by inhibition of intracellular signal transduction cascades. $\mathrm{Br}$ J Dermatol 2004: 151: 565-570.

49. LoPiccolo J, Blumenthal G M, Bernstein W B, Dennis P A. Targeting the PI3K/Akt mTOR pathway: effective combinations and clinical considerations. Drugs Resist Updat 2008: 11: 32-50.

50. Kalyankrishna S, Grandis J R. Epidermal growth factor receptor biology in head and neck cancer. J Clin Oncol 2006: 24: 2666-2672.

51. O'Shaughnessy R F L, Welti J C, Cooke J C etal. AKT-dependent HspB1 (Hsp27) activity in epidermal differentiation. J Biol Chem 2007: 282: 17297-17305.

52. Brunet A, Bonni A, Zigmond $\mathrm{M} J$ et al. Akt promotes cell survival by phosphorylating and inhibiting a forkhead transcription factor. Cell 1999: 96: 857-868.

53. Sarbassov D D, Ali S M, Sengupta S et al. Prolonged rapamycin treatment inhibits mTORC2 assembly and Akt/PKB. Mol Cell 2006: 22: 159-168.

54. Jian X, Yeung R S. Regulation of microtubule-depended protein transport by the TSC2 / mammalian target of rapamycin pathway. Cancer Res 2006: 66: 52585269.

55. Weiske J, Schoneberg T, Schroder $\mathrm{W}$ et al. The fate of desmosomal proteins in apoptotic cells. J Biol Chem 2001: 276: 41175-41181.

56. Li N, Zhao M, Wang J, Liu Z, Diaz L A. Involvement of the apoptotic mechanism in pemphigus foliaceus autoimmune injury of the skin. J Immunol 2009: 182: 711-717.

57. Schmidt E, Gutberlet J, Siegmund D et al. Apoptosis is nor required for acantholysis in pemphigus vulgaris. Am J Physiol Cell Physiol 2009: 296: C167C172.

58. Orlov M D, Chernyavsky A I, Arredondo J, Grando S A. Synergistic actions of pemphigus vulgaris IgG, Fas-ligand and tumor necrosis factor-a during induction of basal cell shrinkage and acantholysis. Autoimmunity 2006: 39: 557-562.

59. Saggar S, Zeichner J A, Brown T T, Phelps R G, Cohen S R. Kaposi's sarcoma resolves after sirolimus therapy in a patient with pemphigus vulgaris. Arch Dermatol 2008: 144: 654-657. 


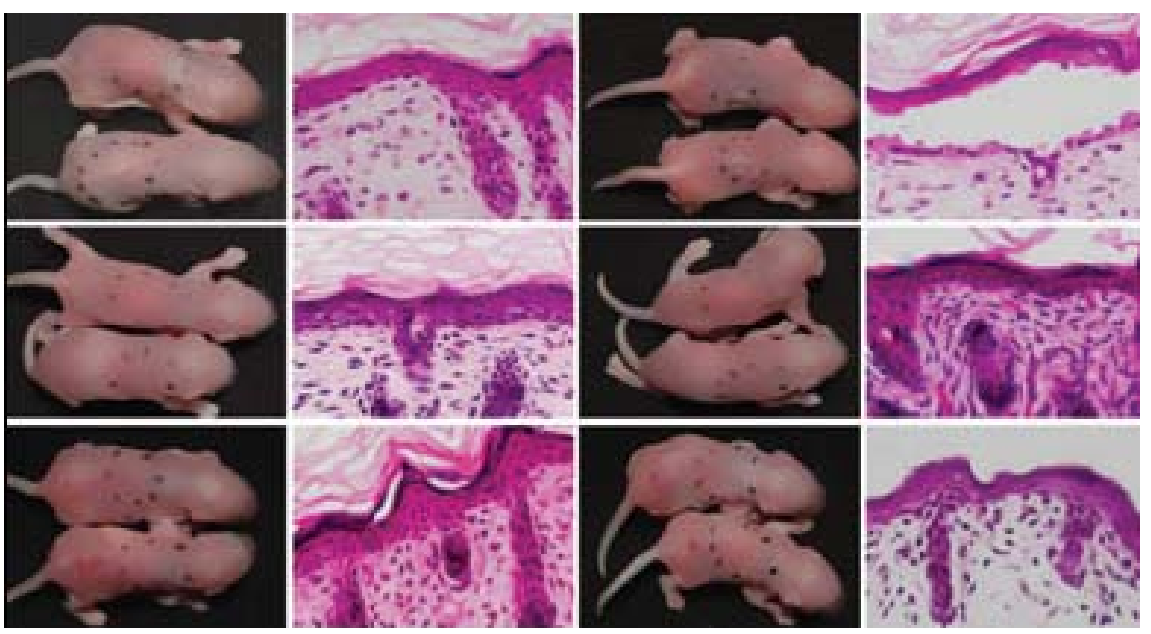

Figure 1. Clinical and histological findings after NHS-IgG and PV-IgG plus inhibitors administration. (a) Neither clinical nor (b) histological findings were evident after NHSIgG administration. (c) After PV-IgG injection, detachment of skin and (d) suprabasal acantholysis could be observed. When mice were pretreated with (e, f) erlotinib, (g, h) PP1, $(i, j)$ rapamycin and $(k, l)$ pan-caspase inhibitor before PV-IgG injection, neither clinical nor histological manifestation was observed. 

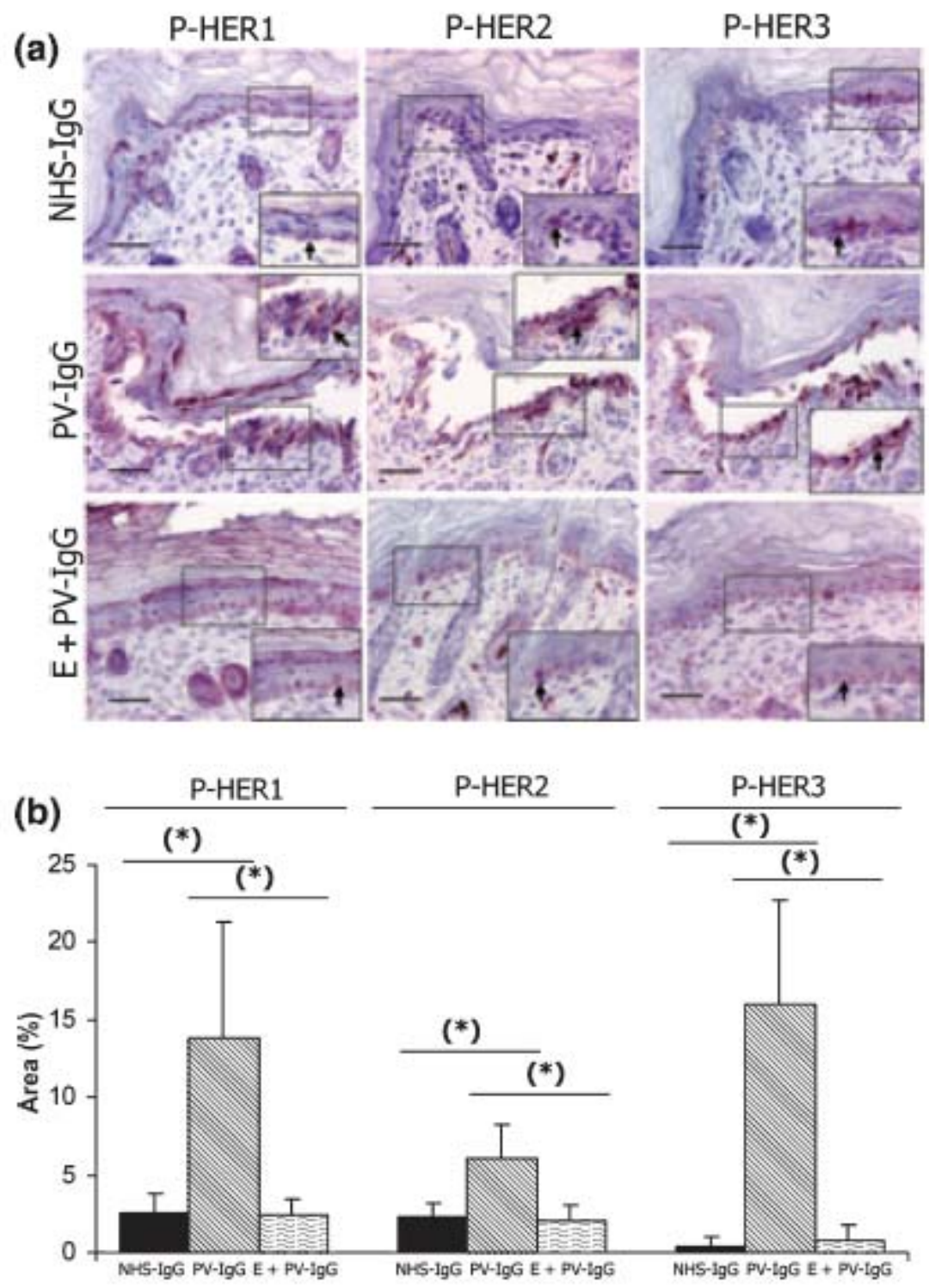

Figure 2. Immunohistochemical (IHC) staining and quantification of expression of activated HER isoforms in basal cells of the epidermis in PV lesions. (a) When mice were injected with NHS-IgG, IHC analysis revealed in the basal layer of the epidermis the presence of a slight expression of P-HER1, P-HER2 and P-HER3 (arrows). These expressions were stronger after injection of PV-IgG and showed an intensive staining in the basal cells of detached and non-detached epidermis (arrows). When mice were pretreated with erlotinib, we observed a decreased expression in basal layer of P-HER1, P-HER2 and P-HER3 compared with that observed after PV-IgG injection (bars $=25$ $\mathrm{lm}$ ). (b) Quantification of expression for activated HER isoforms revealed an increased and significant staining of P-HER1, P-HER2 and P-HER3 in the basal layer of the epidermis after PV-IgG injection to mice, compared with that observed after NHS-IgG injection. After pretreatment of mice with erlotinib, staining decreased significantly for all of three HER isoforms, compared with that observed only after administration of PV-IgG. Data are mean $\pm \mathrm{SD}$; ${ }^{\mathrm{P}}<0.05$. NHS-IgG: non-human serum IgG; PV-IgG: pemphigus vulgaris IgG. 

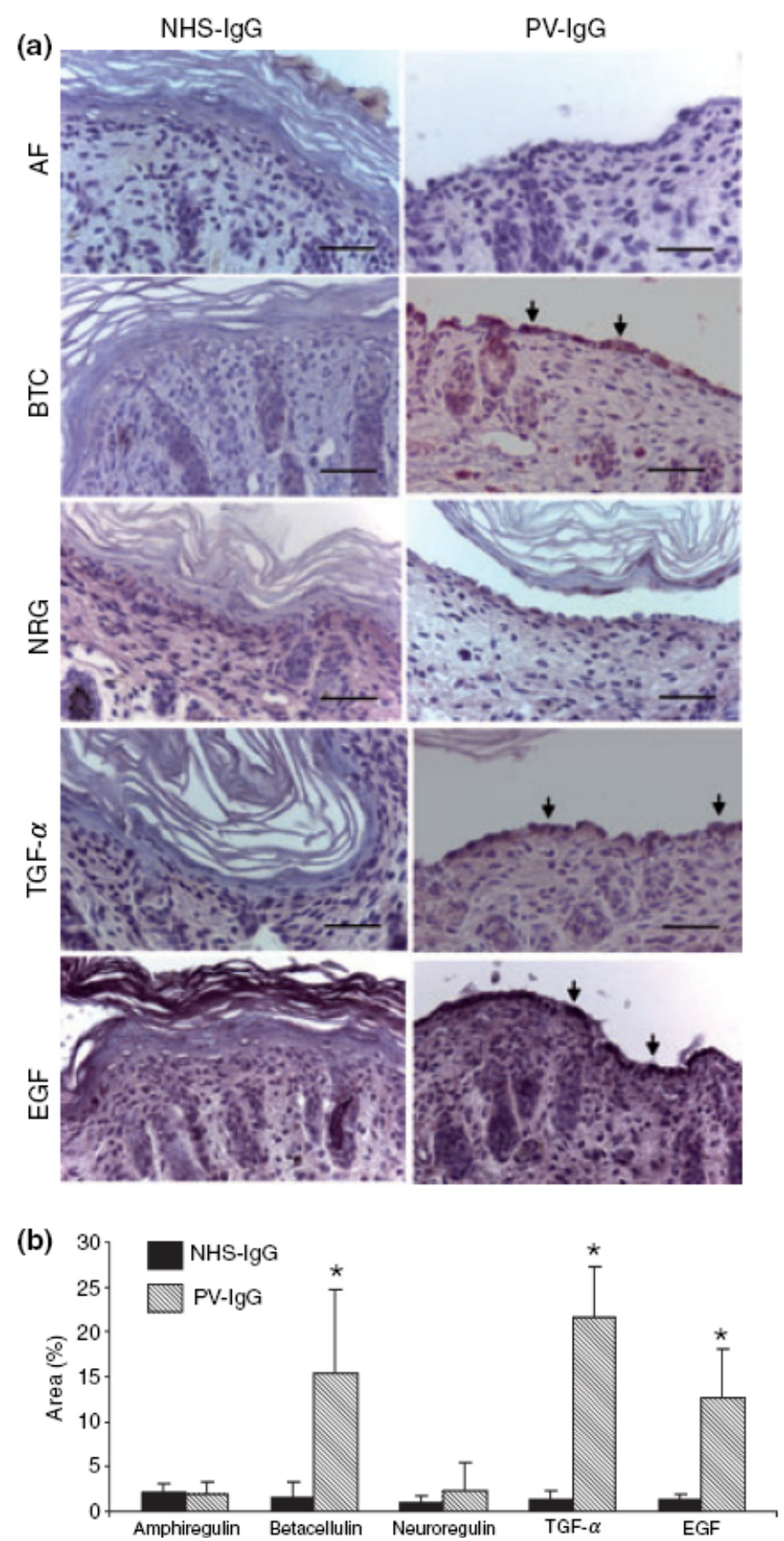

Figure 3. Study of the expression of ligands of HER isoforms by IHC analysis and quantification of their staining in basal cells of the epidermis. Immunohistochemical analysis (a) all ligands studied showed a very slight expression on basal cells of the epidermis. Only betacellulin, TGF-a and EGF showed a more intensive staining localized in basal cells of the epidermis after PV-IgG administration (arrows). Staining for neuroregulin and amphiregulin was similar after both PV-IgG and NHS-IgG administration (bars $=50 \mathrm{~lm}$ ). (b) Quantification of expression of these ligands after PV-IgG injection showed only a higher and significant staining for betacellulin, TGF-a and EGF than that observed after NHS-IgG administration. Data are mean $\pm \mathrm{SD}$; ${ }^{*} \mathrm{P}<$ 0.05. NHS-IgG: normal human serum IgG; PV-IgG: pemphigus vulgaris IgG; AF: amphiregulin; BTC: betacellulin; NRG: neuroregulin; TGF-a: transforming growth factor-a; EGF: epidermal growth factor. 


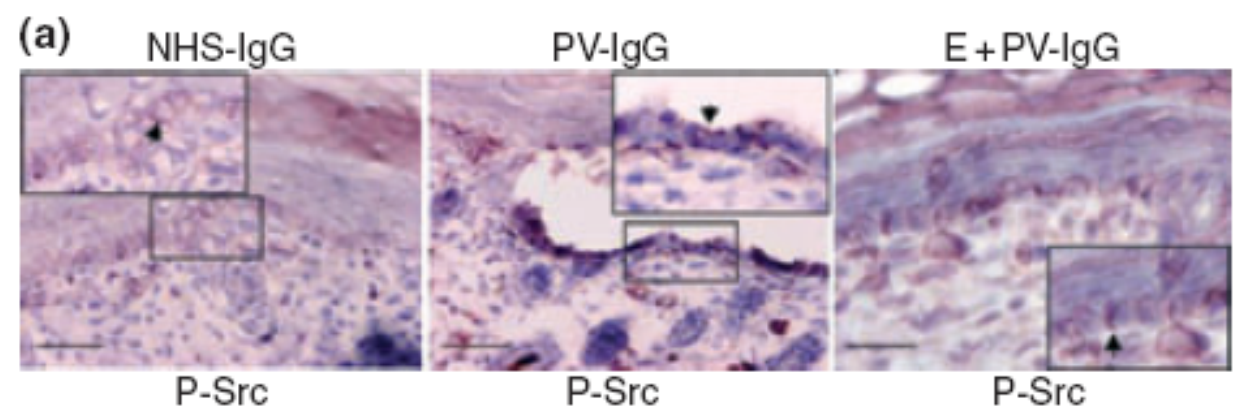

(b)
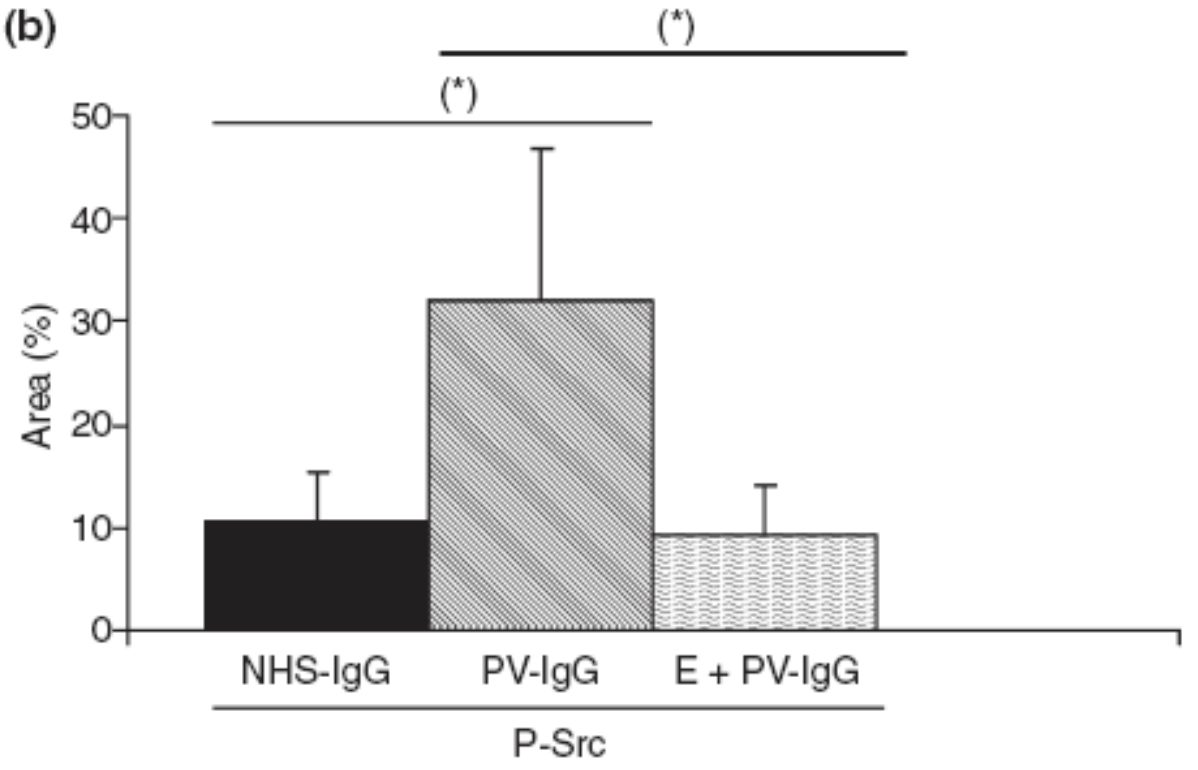

Figure 4. Analysis of phosphorylated Src in the basal cells of the epidermis by immunohistochemial evaluation and quantification expression. Immunohistochemical analysis. (a) Injection of NHS-IgG into mice revealed staining for P-Src in the basal layer of the epidermis and follicular epithelia. After PV-IgG injection, the expression of P-Src was more evident in detached and non-detached basal cells of the epidermis (arrows). When mice were pretreated with erlotinib, the expression of P-Src decreased significantly (bars $=25 \mathrm{~lm}$ ). (b) The quantification of P-Src showed an elevated and significant expression after PV-IgG injection than that found after NHS-IgG administration. When mice were pretreated with erlotinib, we observed a lower and significant quantification of P-Src in basal layer of epidermis than that found after only PV-IgG injection. Data are mean $\pm \mathrm{SD} ; * \mathrm{P}<0.05$. NHS-IgG: normal human serum IgG; PV-IgG: pemphigus vulgaris IgG; E: erlotinib. 
(a)

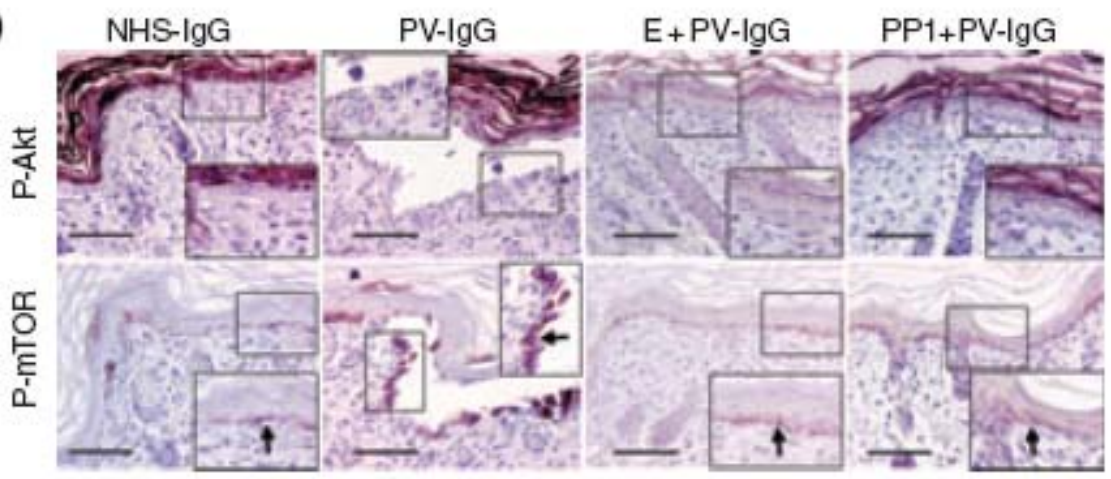

(b)
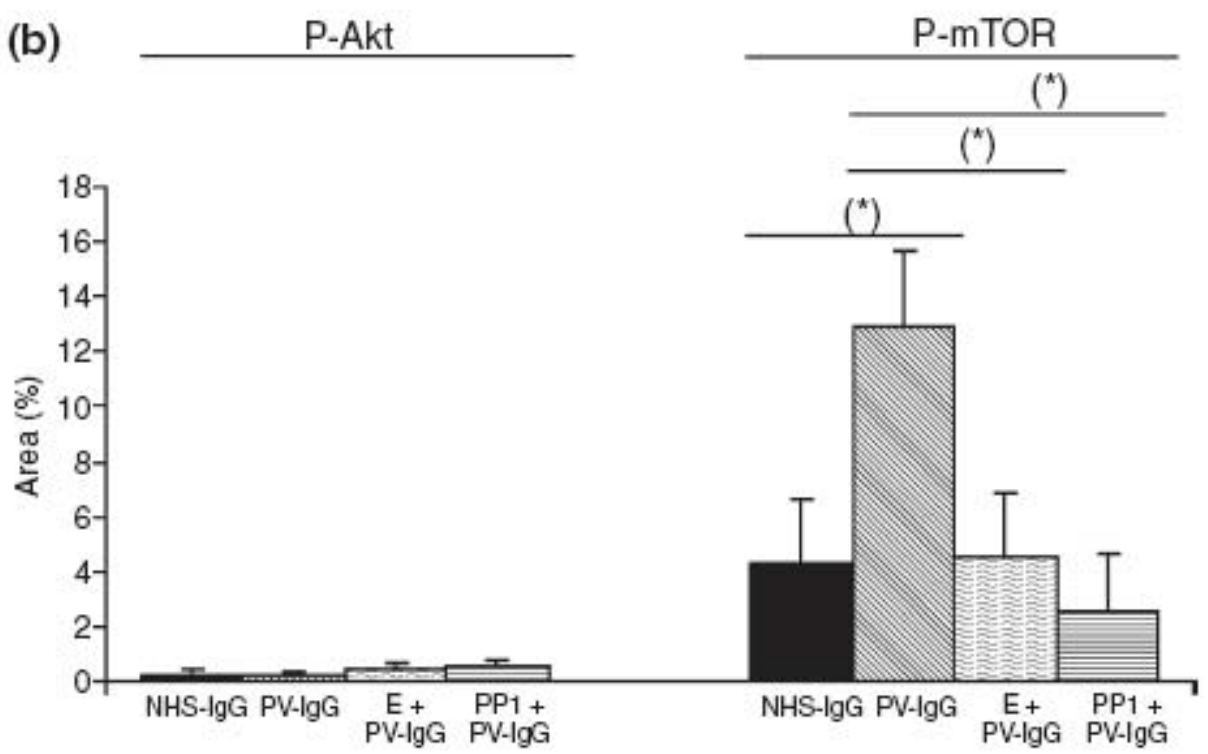

Figure 5. Immunohistochemical analysis and quantification assay of both activated Akt and mTOR in basal cells of the epidermis in mice. (a) Immunohistochemical analysis revealed practically no P-Akt expression, and focal and patchy expression of P-mTOR in the basal cells of the epidermis was observed after NHS-IgG administration. P-Akt was very scantily expressed, and staining of P-mTOR was clearly evident in basal cells of detached and non-detached epidermis, after administration of PV-IgG to mice (arrows). When mice were pretreated with erlotinib, we observed a lower expression of P-mTOR and no changes in expression of P-Akt. When mice were pretreated with rapamycin, we did not observe any changes in the expression of P-Akt. When mice were pretreated with PP1, we observed a lower expression of P-mTOR and no changes in the expression of P-Akt compared with that observed after PV-IgG injection (bars = $25 \mathrm{~lm}$ ). (b) When quantification analysis was carried out, we observed a similar and non-significant difference in the expression of P-Akt after NHS-IgG and PV-IgG administrations. However, expression of P-mTOR showed a higher and significant expression after PV-IgG injection into mice. Pretreatment of mice with erlotinib and PP1 demonstrated no significant differences in the expression of P-Akt, and decreased and significant expression of P-mTOR. Mice pretreated with rapamycin showed no significant changes in the expression of P-Akt. Data are mean $\pm \mathrm{SD}$; ${ }^{*} \mathrm{P}<0.05$. NHSIgG: non-human serum IgG; PV-IgG: pemphigus vulgaris IgG. 
(a)

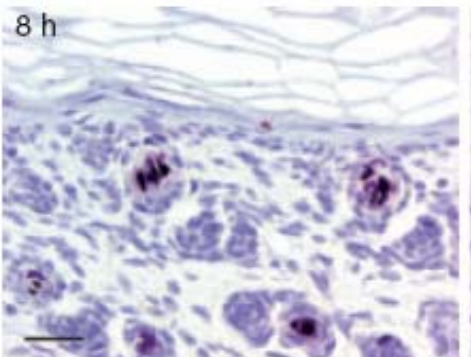
$9 \mathrm{~h}$
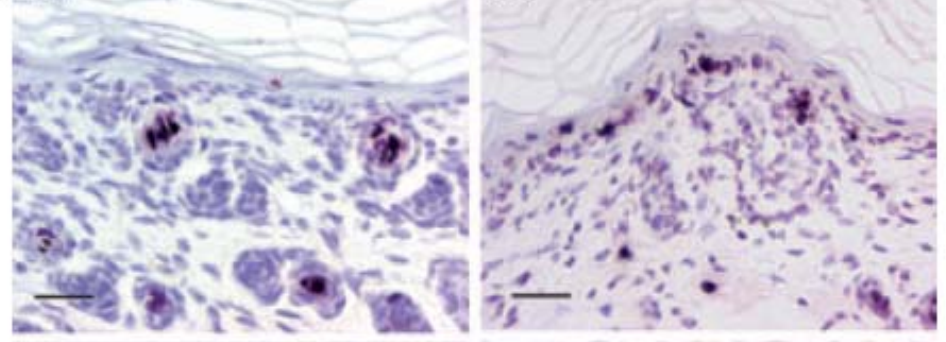

$10 \mathrm{~h}$

$11 \mathrm{~h}$
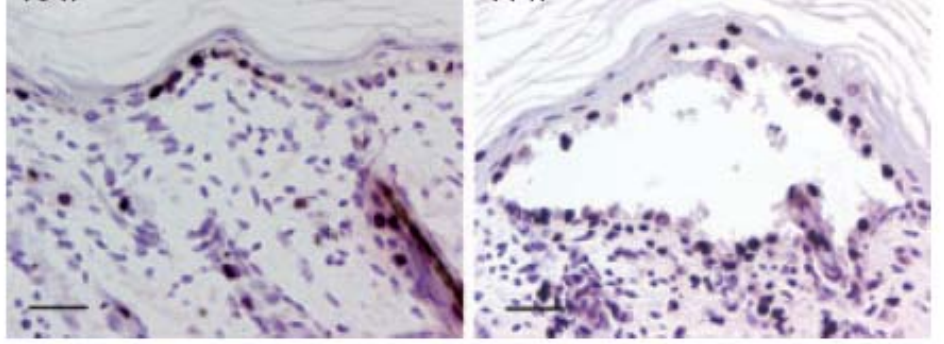

(b)
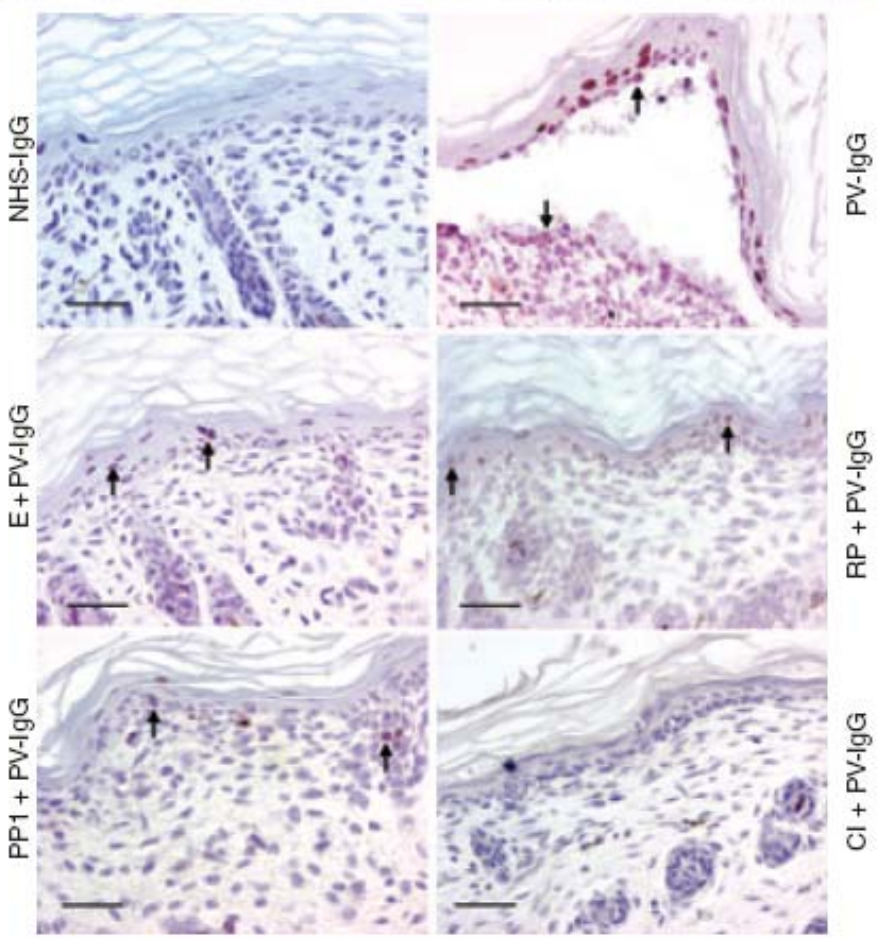

(c)

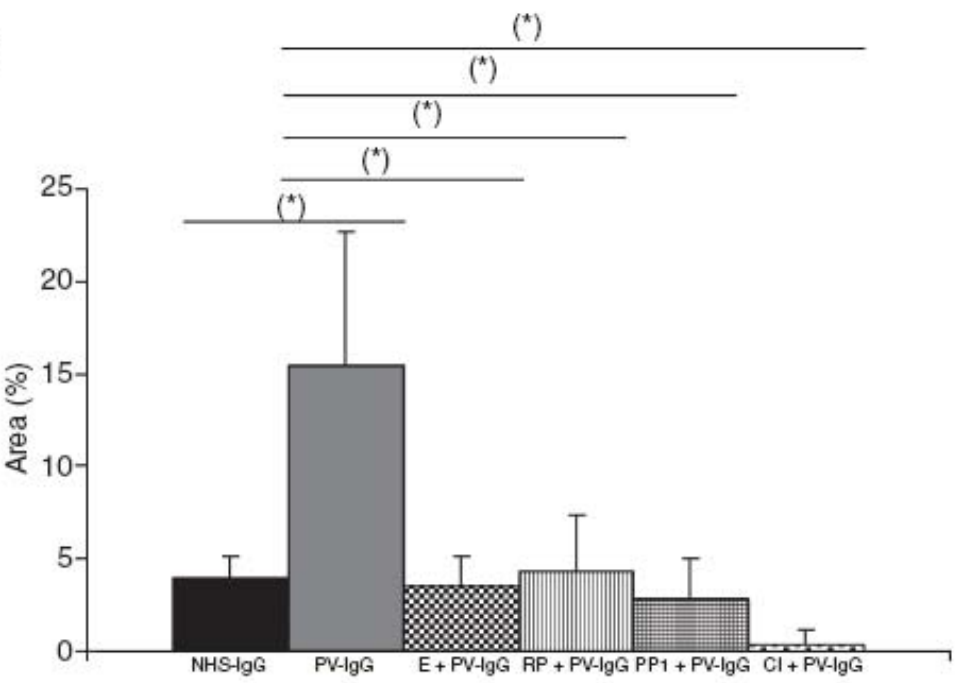


Figure 6. Relationship between apoptotic and suprabasal acantholytic processes. Timing course of the apoptotic process after PV-IgG injection by TUNEL assay. (a) Epidermis of mice injected with PV-IgG began to show the presence of apoptotic cells in the basal layer of the epidermis $8 \mathrm{~h}$ after PV-IgG injection, mainly around hair follicles (arrows). At 9 and $10 \mathrm{~h}$ after PV-IgG injection, apoptotic cells could be seen mainly in basal layer of epidermis (arrows). At $11 \mathrm{~h}$ postinjection of PV-IgG, apoptosis of basal and upper keratinocytes was accompanied by suprabasal acantholysis (arrows) (bars $=50 \mathrm{~lm}$ ). (b) TUNEL assay in epidermis of mice after NHS-IgG and PV-IgG plus inhibitors. (c) Quantification of expression of apoptotic cells in the basal cell of the epidermis. Twelve hours after PV-IgG injection into mice, a higher and more significant presence of TUNEL-positive cells was observed in the basal cells of the epidermis than that after NHS-IgG injection. A decreased and significant expression of apoptotic cells in basal layer of epidermis was observed after pretreatment with erlotinib, rapamycin, PP1 and pan-caspases inhibitor. Data are mean $\pm \mathrm{SD} ; * \mathrm{P}<0.05$. NHSIgG: non-human serum IgG; PV-IgG: pemphigus vulgaris IgG; E: erlotinib; RP: rapamycin; PP1: inhibitor of Src PP1; CI: pan-caspase inhibitor. 


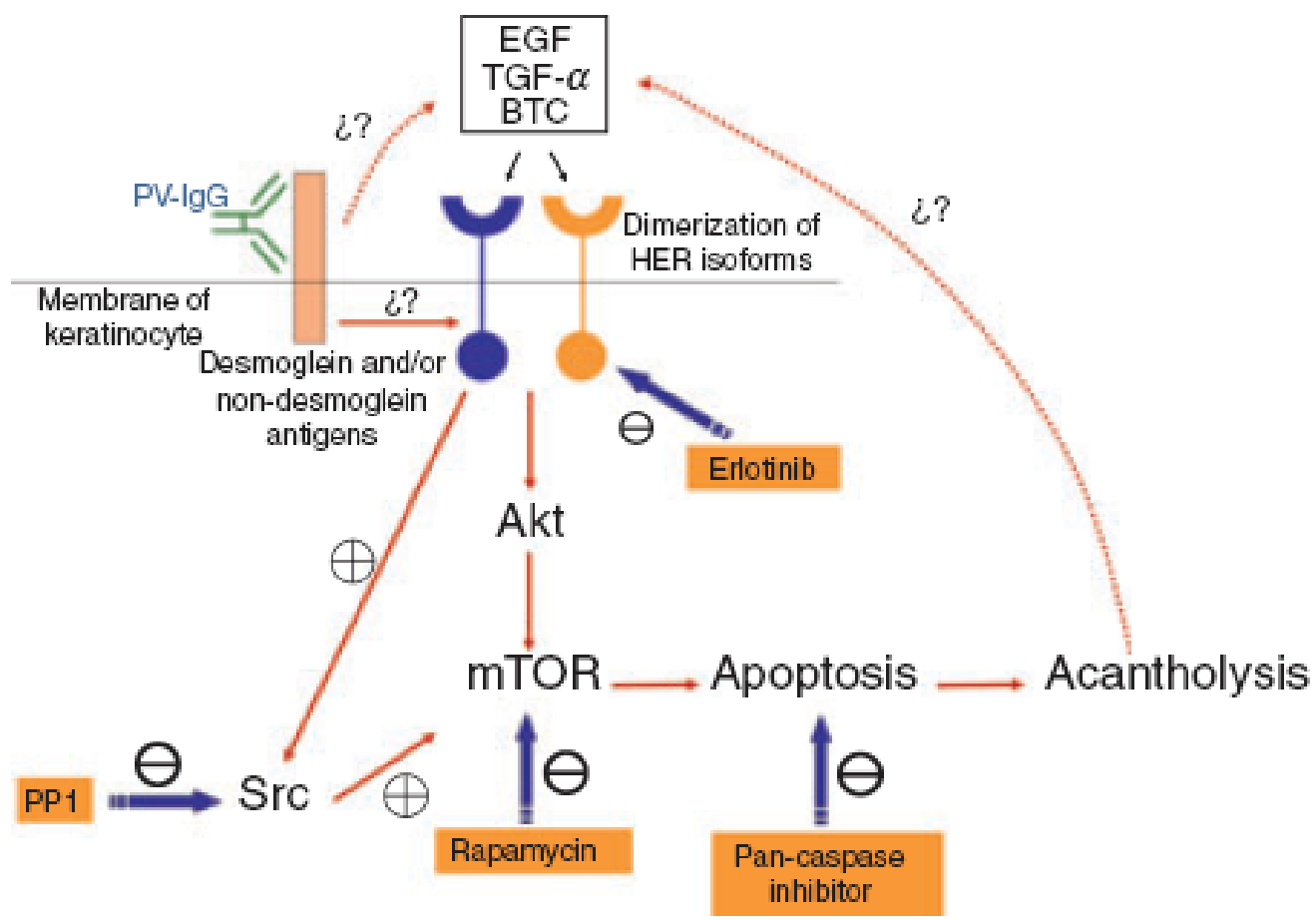

Figure 7. Scheme showing how acantholysis and apoptosis may be produced. An imbalance in Akt/mTOR is involved in PV. Usually, Akt is not found in basal cell layer of epidermis, and mTOR is up-regulated after binding of PV-IgG to desmoglein and / or non-desmoglein antigens. It is not clear if up-regulation of EGF, betacellulin and TGF-a is a consequence of PV-IgG binding to keratinocytes before acantholysis or if it was induced by cell dissociation. 